\title{
The effects of temporal delay and frequency alteration on the speaking rates of children
}

\author{
RICHARD HAM, DONALD FUCCI, and JAMES CANTRELL \\ Ohio University, Athens, Ohio
}

\begin{abstract}
Children's speaking rates under delayed auditory feedback (DAF) do not appear to be significantly affected by the extent of the frequency envelope in the auditory feedback from portable and conventional DAF units. The electroacoustic characteristics of conventional research and portable electronic delayed auditory feedback instrumentation are substantially different. A portable DAF unit has a more limited frequency-response pattern at normal operating intensities than does a conventional DAF unit. However, in this study, analyses of the effects of both types of instruments revealed high correlations between speaking rates. This suggests that both types of instruments are valid tools for modifying children's speaking rates.
\end{abstract}

Delayed auditory feedback (DAF) has been used in research since the early 1950 s. DAF speech occurs when the auditory sidetone is delayed. Lee (1950) first reported the disruptive changes in rate, rhythm, and other speech parameters with DAF (i.e., speakers displayed prolongations, repetitions, blockages, and other speech nonfluencies). Researchers and clinicians have, for many years, used larger DAF units, which produce a mechanical delay of the auditory signal that occurs with movement of recording tape between electromagnetic heads.

DAF has been used with speakers of all ages. Siegel, Fehst, Garber, and Pick (1980) studied DAF effects in three age groups. Significant DAF effects were found for all age groups, with the DAF effects being most pronounced in younger children. The investigators suggested that younger children rely more heavily upon auditory feedback to regulate their speech production than do older children or adults.

DAF has been used as a part of treatment programs for nonfluent speakers (Curlee \& Perkins, 1969; Gregory, 1968; Ryan, 1978; Ryan \& Van Kirk, 1974; Shames \& Florance, 1980; Van Riper, 1970). Nonfluent speakers usually find DAF adversive initially, but reduced nonfluencies and a slowing of speaking rate with DAF can result in an appreciable fluency effect. This allows the speaker an opportunity to practice self-control techniques.

Newer types of portable electronic DAF units appear to present the speaker with a significantly reduced frequency envelope (Ham \& Cantrell, 1982). The more limited electroacoustic characteristics of a portable DAF unit might result in differences in speech under DAF. If different DAF units with significantly different electroacoustic characteristics result in dif-

The authors wish to thank Carolyn McKibben, Larry Wallace, and the children who participated as subjects in this study. The authors' mailing address is: School of Hearing and Speech Sciences, Ohio University, Athens, $\mathrm{OH} 45701$. ferent speech effects, the application of research findings with conventional DAF units to fluency programs using portable DAF units might be compromised.

\section{METHOD}

Subjects

Ten female subjects, ages 10 to 14 years, participated in this study. All subjects were normal speakers of American English and had normal peripheral hearing. The subjects were assigned randomly to one of two groups.

\section{Instrumentation}

A research-quality reel-to-reel tape recorder was used in this study. The recorder was modified to produce an auditory delay of $100 \mathrm{msec}$, matching the delay used on a commercially available portable DAF unit. A General Radio Type 1304 beatfrequency audio generator and a General Radio Type 1521 graphic level recorder were used to determine that the electroacoustic characteristics of the two instruments were different (Figure 1). Standard TDH-39 earphones were used to calibrate intensity settings on both instruments at $55-\mathrm{dB}$ acoustic gain for a $1000-\mathrm{Hz}$ signal using a Brüel and Kjaer (B \& K) Type 2203 sound-level meter and a Type 1613 octave filter set. A Maico MA-20 audiometer was used as a frequency generator for the $1000-\mathrm{Hz}$ tones.

\section{Procedure}

All subjects were familiarized with the "Rainbow Passage" (Fairbanks, 1960) and the alphabet recitation task prior to testing. The first group of subjects read the initial paragraph of the reading passage and then recited the alphabet, first with feedback from the conventional research DAF instrument and then with feedback from the portable DAF instrument. The second group completed the same tasks first under the influence of DAF from the portable unit and then under the influence of the other DAF unit. Speech samples were recorded on electromagnetic tape on a Sony TC-580 reel-to-reel recorder.

\section{RESULTS}

The reading and recitation samples were measured for speaking rates. Mean speaking rates with standard deviations are reported in Table 1. Further analysis, 
Table 1

Means and Standard Deviations (SDs) for Speaking Rates (in Minutes)

\begin{tabular}{lcc}
\hline \multicolumn{1}{c}{ Speech Sample } & Mean & SD \\
\hline Reading (Research Unit) & 1.42 & 0.42 \\
Reading (Portable Unit) & 1.32 & 0.36 \\
Recitation (Research Unit) & 0.53 & 0.12 \\
Recitation (Portable Unit) & 0.51 & 0.12 \\
First Reading & 1.42 & 0.33 \\
Second Reading & 1.32 & 0.45 \\
First Recitation & 0.55 & 0.11 \\
Second Recitation & 0.50 & 0.13 \\
\hline
\end{tabular}

Table 2

Correlations Between Speaking Rates

\begin{tabular}{ccc}
\hline Speech Samples & $\begin{array}{c}\text { Correlation } \\
\text { Coefficients }\end{array}$ & $\begin{array}{c}\text { Probability } \\
\text { Levels }\end{array}$ \\
\hline $\begin{array}{c}\text { Reading on Different } \\
\text { Instruments } \\
\text { Recitations on Different } \\
\text { Instruments }\end{array}$ & 0.80 & 0.006 \\
$\begin{array}{c}\text { Readings/Recitations on } \\
\text { the Same Instrument }\end{array}$ & 0.47 & 0.16 \\
$\quad \begin{array}{l}\text { (Research Unit) } \\
\text { (Portable Unit) }\end{array}$ & 0.62 & 0.05 \\
First and Second \\
$\quad$ Readings & 0.80 & 0.004 \\
First and Second & 0.82 & 0.003 \\
Recitations & 0.52 & 0.11 \\
\hline
\end{tabular}

using an IBM 370 computer system with an SAS statistical package, found strong significant Pearson correlations between portable DAF unit readings and conventional DAF unit readings, between readings and recitations with the same DAF instrument, and between first and second readings regardless of which DAF instrument was employed first to obtain a reading sample (Table 2). Moderate correlations were found between the first and second recitations and between recitations on different DAF units, but these correlations did not reach a .05 level of significance.

\section{DISCUSSION}

The frequency-response range was more limited in the portable DAF unit than in the conventional research DAF unit (Figure 1). The results of this study, however, suggest that researchers and clinicians who use portable DAF instruments might anticipate similar speaking rates with portable and conventional research DAF units at the elevated intensity levels used in this study. Children's speaking rates under DAF do not appear to be significantly affected by the extent of the frequency envelope in the auditory feedback from portable and conventional DAF units.

\section{REFERENCES}

Curlee, R., \& Perkins, W. (1969). Conversational rate control therapy for stuttering. Journal of Speech and Hearing Disorders, 34, 245-250.

FaIrBanKs, G. (1960). Voice and articulation drillbook (2nd ed.). New York: Harper \& Row.

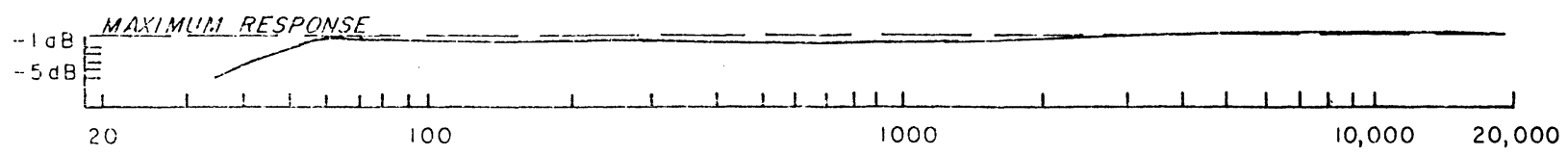

CONVENIIONAL DAF RESEARCH UNIT

FREQUENCY IN CYCLES PER SECOND

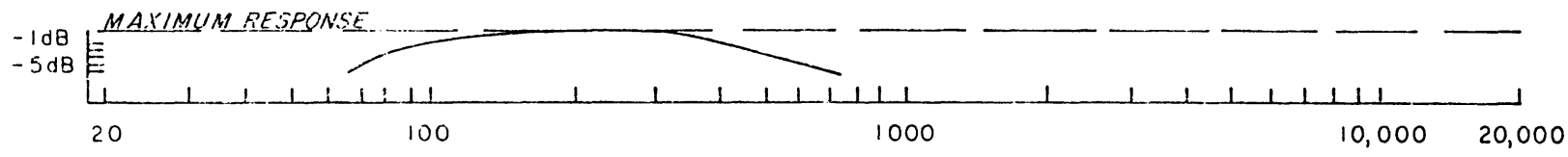

PORTABIE DAF UNIT

\section{FREQUENCY IN CYCLES PER SECOND}

Figure 1. Frequency response characteristics of conventional and portable DAF units. 
Gregory, H. (Ed.) (1968). Learning theory and stuttering therapy. Evanston, IL: Northwestern University Press.

Ham, R., \& Cantrell, J. (1982). [Untitled]. Unpublished manuscript, Ohio University.

LEE, B. (1950). Effects of delayed speech feedback. Journal of the Acoustical Society of America, 22, 824-826.

RYAN, B. (1978). Stuttering therapy in a framework of operant conditioning and programmed learning. In H. Gregory (Ed.), Controversies about stuttering therapy. Baltimore: University Park Press.

Ryan, B., \& VAN Kirk, B. (1974). The establishment, transfer, and maintenance of fluent speech in 50 stutterers using delayed auditory feedback and operant procedures. Journal of Speech and Hearing Disorders, 39, 3-10.

Shames, G., \& Florance, C. (1980). Stutter-free speech, a goal for therapy. Columbus, $\mathrm{OH}$ : Merrill.

Siegel, G., Fehst, C., Garber, S., \& Pick, H. (1980). Delayed auditory feedback with children. Journal of Speech and Hearing Research, 23, 902-913.

VAN RIPER, C. (1970). The use of DAF in stuttering therapy. British Journal of Disorders of Communication, 5, 40-45.

(Manuscript received for publication March 29, 1984.) 